\title{
Procesos Colectivos de interés Público Y FUNCIÓN DE GARANTÍA PARA LA EFECTIVIDAD DE LOS DERECHOS FUNDAMENTALES*
}

\author{
Roberto Omar Berizonce $e^{* * *}$
}

"El edificio de la democracia tiene un millón de ventanas, cada una abierta para recibir las mejores iniciativas a fin de que, con voz fundacional, podamos escribir el guión superador".

Augusto Mario Morello ${ }^{1}$

\begin{abstract}
RESUMEN
Los conflictos colectivos de interés público, que vienen suscitando el creciente compromiso de los jueces en Argentina, Colombia, Brasil y otros países de la región, ponen en debate el ejercicio y los alcances de las funciones de garantía que en el Estado Democrático de Derecho corresponden al Poder Judicial. Se intenta demostrar la regla que afirma la autoridad de los jueces para tutelar los derechos fundamentales vulnerados, en vías del control de constitucionalidad y de convencionalidad, sin mengua de las políticas públicas de resorte de los otros poderes de gobierno. Como correlato de tales intervenciones, se sostiene, el proceso judicial se convierte en un espacio abierto y transparente de democracia deliberativa para la búsqueda de soluciones estructurales, que legitima al Poder Judicial y contribuye notoriamente al afianzamiento de la institucionalidad republicana.
\end{abstract}

* Este trabajo constituye una versión corregida y ampliada de otro, del mismo título, publicado en la Revista de Derecho Procesal (Argentina), Rubinzal-Culzoni ed., Santa Fe, 2012, número extraordinario, pp. 481-502.

** Profesor Emérito de la UN La Plata, Argentina. Presidente Honorario del Instituto Iberoamericano de Derecho Procesal.

1 MORELlO, Augusto Mario. La línea de partida de la Argentina posible, FEN, Col. Escrib. Prov. Bs. As., La Plata, 2002, p. 115. 
Palabras clave: Función judicial de garantía, conflictos colectivos de interés público, equilibrio de poderes, legitimación de los jueces, institucionalidad republicana.

\begin{abstract}
Conflicts of public interest groups, that have been favoring the growing commitment of judges in Argentina, Colombia, Brazil and other countries in the region, give rise to discussions that question the exercise and scope of the security functions that correspond to the judiciary in the democratic rule of law. There have been intents to prove the rule that affirms the authority of judges to protect the fundamental violated rights, in order to control both constitutionality and conventionality, without diminishing public policies that influence other branches of government. As a corollary of such interventions, it is argued that the judicial process becomes an open and transparent space of deliberative democracy for finding structural solutions, which legitimizes the judiciary and contributes significantly to the strengthening of republican institutions.
\end{abstract}

Key words: Judiciary function of warranties, collectives conflicts of public interest, balance of powers, empowerment of judges, republican institutions.

\title{
I. FUNCIONES ESTATALES DE GOBIERNO Y DE GARANTÍA
}

1. En el modelo denominado Estado Constitucional de Derecho, o de Justicia, o Estado Democrático Constitucional ${ }^{2}$, se destaca la consolidación de las conquistas liberales tradicionales; de los principios y derechos sociales que persiguen la igualdad sustancial; tanto como los de la solidaridad y de la comunidad que resalta los derechos colectivos y difusos. Lo novedoso es que se incorpora el derecho fundamental a la participación de todas las personas, en determinados niveles, para la configuración de las decisiones de los poderes del Estado. Se alude así a una "cuarta dimensión" de los derechos fundamentales. En ese esquema, el proceso jurisdiccional, entre otros instrumentos, se inserta como un espacio privilegiado para la búsqueda y consecución de las soluciones compositivas de los conflictos de interés general, constriñendo al diálogo fructífero entre los propios poderes públicos y los directamente involucrados, imprescindible en una sociedad multicultural caracterizada por la pluralidad y el disenso.

En su evolución, el proceso civil en general es ahora enzalzado, paradójica y quizás excesivamente, como un instrumento decisivo para la realización no solo

2 ZANETTI Jr. H., A teoría da separaçâo de poderes e o Estado Democrático Constitucional: funçôes de goberno e funçôes de garantia en Pellegrini Grinover A. y Watanabe K., O controle jurisdiccional de políticas públicas, Forense, R. de Janeiro, 2011, pp. 33 y ss., especialmente, pp. 42-43. 
del derecho y su efectivización en concreto, sino, además de un nuevo modelo de Estado en el cual se acentúa la participación de los sujetos, personas individuales y colectivas, en la conformación de las decisiones propias de la totalidad de los poderes estatales. Desde esa visión, la tensión entre la alegación de falta o insuficiencia de una política pública y la previsión normativa de un derecho fundamental "sensible" que demanda respuesta, se dirime a través del proceso judicial que ofrece un modelo normativo típico, propio de la denominada democracia deliberativoprocedimental. El Poder Judicial, y los jueces, están convocados entonces a ejercer un novedoso papel de moderadores, componedores para el correcto funcionamiento del sistema constitucional de frenos y contrapesos, cada vez que se demuestre una "disfunción política" de la administración o de la legislatura, o sea un desvío del natural curso del interés público que por mandato constitucional merece protección y que, por ello mismo, implica una quiebra de la legalidad que abre camino al control jurisdiccional ${ }^{3}$.

2. Por otro lado, la superación de la conceptualización clásica de la división de poderes y su transmutación en separación de funciones, abrió camino hacia una nueva categorización en funciones de gobierno y funciones de garantía. Las primeras son propias de los poderes políticos, a los que corresponde el ejercicio de las opciones sobre políticas públicas y estrategias de desenvolvimiento. Las funciones de garantía, en cambio, quedan a cargo del Poder Judicial y otras instituciones como el Ministerio Público y demás entes controladores. Mientras el Legislativo y el Ejecutivo se legitiman a partir de la representación popular, los jueces ejercen su legitimidad como órganos superiores en la aplicación de la Constitución y de las leyes, colocándole a los poderes políticos límites y vínculos definidos por los derechos fundamentales. El equilibrio entre unos y otros deriva de las propias y consustanciales limitaciones del Poder Judicial, que son materiales y jurídicas. No solo está ceñido al derecho y a la capacidad para fundamentar adecuada y racionalmente sus decisiones, tanto como a las restricciones a la hora de su ejecución; sino, además y principalmente, a los límites propios de una función de garantía supletoria, subsidiaria o secundaria, dirigida tan solo a colmar las lagunas derivadas de la inefectividad contingente del obrar de los poderes políticos ${ }^{4}$.

3. Las diversas cuestiones que plantea el ejercicio de la función de garantía que corresponde a los jueces remiten genéricamente a la denominada dimensión organizacional y procedimental de los derechos fundamentales, como instrumentos adecuados para su efectivización en concreto. La intervención judicial resulta imprescindible para ello. Ahora bien, en tanto las decisiones hayan de influir en las políticas públicas, uno de los mayores desafíos de los jueces está constituido por

\footnotetext{
3 Op. cit., pp. 44-47, con remisión, entre otros autores, a FERRAJOLI L., Teoría de los derechos fundamentales.

$4 \quad$ Op. cit., pp. 51-53.
} 
la necesidad de armonizar y conjugar no solo el ejercicio de la función de control con las potestades de los órganos político -cuestión central que se aborda más adelante-, sino también los derechos individuales y los colectivos; los que son de cada uno y los que pertenecen a todos. Se trata de evitar, en este último aspecto, que por vía de la tutela de los derechos individuales se termine desconociendo o menoscabando los de los otros individuos en similares circunstancias, que integran la dimensión colectiva. Las conocidas objeciones en relación a la tutela judicial individual, su "egoísmo" de frente a los derechos que son de todos, no pueden naturalmente llevar a su exclusión; pero también es cierto que es preciso emprender ajustes y minimizar sus efectos negativos ${ }^{5}$. Debe lidiarse, en verdad, con complejas cuestiones que exceden en mucho el ámbito delimitado del actuar judicial, y que son propias de las políticas públicas en general. La búsqueda de racionalidad y eficacia en el plano de las estrategias de realización de los derechos fundamentales, y de los derechos sociales en particular, remite a postulaciones diversas, entre ellas, la preferencia (aunque no exclusividad) de la canalización de los reclamos por las acciones colectivas y preventivas, el perfeccionamiento de los procedimientos administrativos, el auspicio del mayor control social, incluyendo la participación efectiva en la definición del presupuesto público y su ejecución, para, en su conjunto, asegurar mayor equidad de todo el sistema prestacional ${ }^{6}$ y que constituyen uno de los objetos centrales de estas disquisiciones, por las singularidades que se denotan en el ejercicio de la función de garantía.

Dentro de ese esquema ocupan un lugar prominente los denominados conflictos colectivos de interés público, cuyas características típicas se ha ocupado de analizar la doctrina ${ }^{7}$ y que constituyen uno de los objetos centrales de estas disquisiciones, por las singularidades que se denotan en el ejercicio de la función de garantía.

\section{LOS LÍMITES AL EJERCICIO DE LA FUNCIÓN DE GARANTÍA JUDICIAL}

1. Los límites y fronteras que separan las funciones políticas de aquellas otras de control se muestran, desde luego, difusas, con contornos esquivos. En abstracto puede afirmarse que no es que los jueces deban abstenerse de toda consideración acerca de las políticas públicas, sino que deben comenzar por tener en cuenta en

5 SARLET I.W., Dereitos fundamentais e processo, RePro, no 199, 2011, pp. 38-39. Sin embargo, el derecho de cada persona a postular, siquiera sea individualmente, ante la justicia, el reconocimiento de sus prerrogativas, termina por reforzar la esfera pública no solo como instrumento de participación social sino, además, como estímulo para el control de las políticas públicas a través de los pronunciamientos jurisdiccionales.

6 SARLET I.W., Op. cit., pp. 29-30.

$7 \quad$ Nos permitimos remitir a nuestro trabajo Los conflictos de interés público, RDP, 2011-2, pp. 69 y ss., y especialmente a la profusa bibliografía que allí se cita. Asimismo: Activismo judicial y participación en la construcción de las políticas públicas, en El Derecho Procesal en vísperas del Bicentenario, RDP número extraordinario, 2010, pp. 169 y ss.. 
sus decisiones que tales políticas deben ser necesariamente inferidas de las finalidades perseguidas por los poderes políticos ${ }^{8}$. Pero, sin embargo, como en definitiva éstos, a su vez, deben acatar los mandatos constitucionales y los valores esenciales privilegiados por la comunidad, el escrutinio de correspondencia entre las políticas públicas y los derechos fundamentales queda en última instancia en manos de los jueces. Y, con mayor razón, en los casos de omisión disfuncional legislativa. Sin perder de vista, naturalmente que la función de control resulta tan solo auxiliar, complementaria y no sustitutiva, con el fin de coadyuvar al logro de las finalidades perseguidas.

Es que como se ha sostenido ${ }^{9}$ no corresponde a los jueces, como principio, la configuración de las políticas, sino la tarea de confrontar el diseño de las asignadas por los poderes respectivos con los estándares jurídicos superiores involucrados y, en caso de detectar divergencias, efectuar el reenvío correspondiente para su readecuación. Cuando la omisión es absoluta, deberá reprochar la inactividad y poner la cuestión en la agenda de aquellos. El interrogante más crítico se plantea cuando se verifica una grave omisión o la falta absoluta de involucramiento de los otros poderes. Según las circunstancias, los jueces podrán, en esos supuestos excepcionales, prudentemente, tentar el diseño de las medidas que consideren necesarias; siempre a salvo las potestades políticas de los otros poderes ${ }^{10}$.

Los tribunales pueden ser un espacio más desde el cual promover la construcción de reglas de derecho y de políticas públicas, que estarán a cargo de los otros poderes del Estado, especialmente en temas estructurales y trascendentes, siempre en el marco de las circunstancias del caso y con sujeción al principio de prudencia judicial ${ }^{11}$. Se requiere un análisis estratégico e integral sobre el núcleo del conflicto y una sincera reflexión sobre las posibilidades reales de aproximación a la solución deseada y, además, al efectivo cumplimiento del mandato judicial.

Es que la autoridad de los jueces surge de los propios límites que ellos, por sí mismos, imponen a la función a través de la cual ejercen el poder. La judicatura -como afirma O. FISS- sucita respeto porque está aislada de la política e implicada en un diálogo especial con la sociedad, a través de las reglas del proceso y la justificación de sus decisiones con base en razones socialmente aceptables. Si se admite

NINO C., Introducción al análisis del derecho, Astrea, Bs. As., 1980, 2a ed., p. 432.

9 ABRAMOVICH V., Acceso a la justicia y nuevas formas de participación en la esfera politica, en La ciencia del Derecho Procesal Constitucional... Homenaje argentino a Héctor FixZamudio..., Rubinzal Culzoni, Santa Fe, 2009, v. II, p. 449. SALGADO J.M., Tutela individual homogénea, Astrea, Bs. As., 2011, pp. 140-141.

10 Sobre las diversas posturas en cuanto al escalonamiento y los diferentes grados del involucramiento judicial: SALGADO J.M., Op. cit., p. 141 y nota 105; pp. 343-344.

11 CATALANO M., Proactividad sin arrebato, La Ley, 2012-B, supl. 28-2-12, nota a fallo 116.106, CSN, 20-12-11, "Provincia de Santiago del Estero c. Cía. Azucarera Concepción S.A. y otro, s. amparo ambiental". 
su participación en la construcción de las políticas públicas es porque la función judicial tiene un contenido esencialmente público, más (o además) que resolver conflictos consiste en dar significado y expresión concretos a los valores públicos contenidos en el derecho, es decir, los que definen una sociedad y le confieren su identidad y coherencia ${ }^{12}$.

2. Una de las cuestiones centrales a que remite el deslinde entre funciones políticas de gobierno y funciones judiciales de control auxiliar de las políticas públicas y los límites en el ejercicio de estas últimas, están referidas a la disposición y provisión de loa fondos públicos necesarios para su ejecución; y ello remite a la observancia del mínimo existencial, del principio de razonabilidad y de la reserva de lo posible ${ }^{13}$, que son propias de los supuestos que encuadran en el denominado "paradigma de la escasez"14, que impera a la hora de satisfacer los derechos económicos, sociales y culturales fundamentales.

El reconocimiento del derecho fundamental a un "mínimo existencial" encuentra sustento en la idea de respeto y consideración, por parte de la sociedad y del Estado, por la vida de cada persona que, desde el imperativo categórico kantiano, debe ser siempre tomada como un fin en sí mismo, en sintonía con la dignidad inherente a todo ser humano. Como señala RAWLS ${ }^{15}$, existen bienes primarios o necesidades de las personas que constituyen elementos necesarios al reconocimiento de una condición ciudadana de acuerdo con los propósitos de justicia política. Por debajo de cierto nivel de bienestar (material, social, educacional, cultural, etc.) las personas no están en condiciones de formar parte de una sociedad como ciudadanos $\mathrm{y}$, mucho menos, como ciudadanos libres e iguales. El derecho fundamental al mínimo existencial engloba genéricamente el contenido de otros diversos derechos fundamentales resumiéndose en el principio de la dignidad de la persona humana, comprensivo a la vez de los derechos a la salud, a la educación, a la vivienda, a la calidad ambiental, a la vida saludable ${ }^{16}$. Están en juego ideales preciados, de impor-

12 FISS O., The Law as It Could Be, 2003 (traducción castellana: El derecho como razón pública, Marcial Pons, Madrid-Barcelona-Bs.As., 2007, trad. E. Restrepo Saldarriaga, que seguimos aquí), pp. 17 y ss., 23, 26 y ss., 30, 34, 78, 88.

13 En Brasil se ha instalado un intenso debate en torno de estos tópicos. En San Pablo se llevó a cabo un seminario sobre $O$ controle jurisdiccional de políticas públicas (abril 2010), coordinado por los profesores PELLEGRINI GRINOVER, A. y WATANABE, K. Ulteriormente, se publicó bajo el mismo título la obra colectiva ya citada, O controle jurisdiccional de políticas públicas, 2011. Seguimos aquí algunas de sus principales conclusiones.

14 Sobre la caracterización de los diversos paradigmas de la intervención y control de las políticas públicas y, especialmente, el de la escasez: GROSSMAN L.S., Escasez e igualdad. Los derechos sociales en la Constitución, Libraria, Bs. As., 2008, pp. 37 y ss.

15 RAWLS J, El liberalismo político, Grijalbo Mondadori, Barcelona, trad. A. Domenech, 1996, p. 211 y ss., 220-224.

16 FENSTERSEIFER T., O controle judicial das políticas públicas..., RePro, 198, 2011, pp. 110111. 
tancia suprema ${ }^{17}$ o, en la feliz expresión del STF de Brasil, derechos constitucionales "impregnados de un sentido de esencial fundamentalidad" 18 .

Ahora bien, ese "mínimo existencial" adquiere sentido cuando se lo vincula al deber del Estado de proveer las expensas presupuestarias necesarias para acordarle efectividad, de ahí que los poderes políticos solo cumplen la manda constitucional en tanto arbitren los medios económicos para asegurar la "reserva de lo posible", es decir las disponibilidades financieras necesarias. Como bien se ha señalado ${ }^{19}$, en realidad la cláusula de la reserva de lo posible se traduce en un binomio que comprende, por un lado, la razonabilidad de la pretensión individual-social deducida y, de otro, la existencia de posibilidad financiera del Estado. Si los poderes de gobierno actuaren de un modo irrazonable afectando aquel núcleo intangible necesario para asegurar el "mínimo existencial" se justificará la intervención judicial. Ello será legítimo a condición de que esté comprobado que la exclusión del beneficio que se reclama resulte irrazonable a la luz de la Constitución, en función del beneficio que se obtendría y la magnitud del esfuerzo económico requerido ${ }^{20}$. Bajo tales circunstancias, si el Estado alegare la falta de recursos para exonerarse, deberá probarlo; y si ello quedare acreditado, los jueces podrán imponer que se previsionen las partidas necesarias en el siguiente proyecto legislativo, o la transferencia de partidas disponibles para su afectación; bajo apercibimiento de las sanciones que correspondieren. Doctrina que en lo sustancial, ha receptado el STF de Brasil.

3. Por último, aunque no menos principal, la intervención de los jueces presupone un novedoso modelo de proceso y de gestión, en el que se abre un "diálogo" ("método dialogal") con la administración pública o los entes involucrados, especialmente para acopiar informaciones sobre las políticas públicas, examinar si fuere necesario el presupuesto; y, aún, en la etapa de ejecución de los pronunciamientos. El contradictorio se amplía en el marco de audiencias públicas, inclusive por la intervención de amicus curiae. La fundamentación de las decisiones requiere un plus argumentativo y de motivación rigurosa, en especial para sustentar las selecciones ponderativas.

17 GROSSMAN L.S., Op. cit., pp. 78-85.

18 FARICELLI DE MENDONÇA P., O papel do juiz na efetiva implementaçâo da política pública. Como administrar a implementaçâo?, en PELLEGRINI GRINOVER, A. y WATANABE, K. coord., Op. cit., p. 413, donde se refiere al Recurso Extraordinario n 482.611, voto del Ministro Celso de Mello, recaído en proceso donde se debatía la ejecución de un programa de acción social en defensa de niños y adolescentes víctimas de abuso y/o explotación sexual.

19 PELLEGRINI GRINOVER A., O controle de políticas públicas pelo Poder Judiciário en RePro, $\mathrm{n}^{\circ} 164,2008$, pp. 9 y ss., especialmente pp. 13-15. La versión castellana se publica en RDP, $E l$ Derecho Procesal en vísperas del Bicentenario, 2010, pp. 319 y ss., trad. de L.J. Giannini. 
Los conflictos de interés público o estratégicos involucran derechos fundamentales colectivos, canalizándose a través de los denominados litigios de derecho público, cuyas características típicas nos hemos ocupado de reseñar en otro lugar ${ }^{21}$.

\section{El EJERCICIO de LA FUNCIÓN DE GARANTía EN LOS PRONUNCIAMIENTOS DE LA CSN ARGENTINA}

En lo que sigue intentaremos una aproximación general a la doctrina que se desprende de los pronunciamientos de la CSN que se considera van marcando rumbos en tan complejas cuestiones. En primer término, y por vía de principio, ha de considerarse que el ejercicio del control encomendado a la justicia sobre los actos $\mathrm{u}$ omisiones de otros poderes del Estado se funda en la premisa que corresponde al Poder Judicial de la Nación, de buscar los caminos que permitan garantizar la eficacia de los derechos y evitar que éstos sean vulnerados, como objetivo fundamental y rector a la hora de administrar justicia, sin que ello constituya una intromisión indebida del Poder Judicial cuando lo único que hace es tender a tutelar los derechos, o suplir omisiones en la medida en que dichos derechos pueden estar lesionados ${ }^{22}$. Y aún, en el ejercicio del aludido control los jueces están obligados a tomar un rol activo y desplegar particular energía para hacer efectivo el mandato constitucional dirigido a la protección de los derechos fundamentales ${ }^{23}$.

Sin embargo, en particular, no les compete resolver cuestiones que son privativas de los otros poderes del Estado, como son las de política económica ${ }^{24}$, ni desde luego imponerles su criterio de conveniencia o eficacia económica o social ${ }^{25}$, ni pronunciarse sobre el acierto o el error, el mérito o la conveniencia de las soluciones legislativas ${ }^{26}$, por lo que no les corresponde revisar actos normativos que

21 Los conflictos de interés público, Op. cit., especialmente pp. 78-82. Asimismo: LORENZETTI R.L., Justicia colectiva, Rubinzal Culzoni, Santa Fe, 2010, pp. 239-244. SALGADO J.M., El amparo colectivo, en FALCON E.M. director, Tratado de Derecho Procesal Constitucional, Rubinzal Culzoni, Santa Fe, 2010, v. 2, pp. 339 y ss.

22 CSN, L.733. XLII, 13-2-07, “Lavado c. Prov. de Mendoza”. En el mismo sentido, D. 587.XLIII, 18-9-07, "Defensor del Pueblo de la Nación c. Estado Nacional y Prov. de Chaco".

23 Por caso, tratándose de la tutela del medio ambiente, que constituye un bien colectivo perteneciente a la esfera social y transindividual (20-6-2006, "Mendoza Beatriz S. y ot. c. Estado Nacional y ot., La Ley, 2006-D, p. 86, consid. 18). O estando en cuestión la seguridad de una represa, lo que convirtió en un imperativo la garantía de la seguridad de las personas y de los bienes (3-3-2009, “Rozniatowski R.C. c. -EN-Secretaria de Energía de la Nación”, La Ley, 2009C, p. 272).

24 Fallos, 315:1820, consid. $8^{\circ}$ y su cita.

25 Fallos, 311:1565.

26 Fallos, 314:424. 
aunque obedecen a un criterio opinable, no exceden lo que es propio de la función legislativa ${ }^{27}$.

En esa misma línea, reiteradamente el Alto Tribunal de la Nación ha sostenido que la misión más delicada de la Justicia es la de saber mantenerse dentro de su jurisdicción, sin menoscabar las funciones que incumben a los otros poderes ni suplir las decisiones que ellos deben adoptar para solucionar los problemas que se suscitan. Todo ello, sin perjuicio del ejercicio del control posterior destinado a asegurar la razonabilidad de esos actos y a impedir que se frustren derechos cuya salvaguarda es deber indeclinable del Tribunal ${ }^{28}$.

Su función suprema -como expresó en uno de sus precedentes ${ }^{29}-$ le impone asumir delicadas responsabilidades institucionales, cuyo ejercicio exige -con marcado énfasis- el deber indeclinable de sopesar con un grado sumo de prudencia las consecuencias individuales, sociales y económicas que generan sus decisiones.

2. En un caso paradigmático sobre el deslinde y ensamble de las respectivas competencias -in re "Badaro" ${ }^{30}$-, sostuvo la Corte que, estando en cuestión la movilidad de los haberes jubilatorios y desde que se trata de una previsión con profundo contenido social, el precepto constitucional del art. 14 bis se dirige primordialmente al legislador, que es quien tiene la facultad de establecer los criterios que estime adecuados a la realidad, mediante una reglamentación que presenta indudable limitación, ya que no puede alterarla (art. 28). Pero si por el cambio de las circunstancias la solución legal, correcta en su comienzo, se torna irrazonable, el cumplimiento de la garantía en juego atañe también a los restantes poderes públicos que deberán, dentro de la órbita de su competencia, hacer prevalecer el espíritu protector que anima al precepto contenido en el art. 14 bis $\mathrm{CN}$, dentro del marco que exigen las diversas formas de justicia. En consecuencia, sin fijar una pauta mínima para la actualización, cabe instar al P.E., y al Congreso a que "en un plazo razonable" adopten las medidas pertinentes. Sin perjuicio de su control a posteriori ${ }^{31}$.

3. De ello puede deducirse que la función de garantía que corresponde al órgano jurisdiccional se ejercita a través de diversas intervenciones en varias secuencias.

$27 \quad$ Fallos, 260:102 y sus citas; 298:286; 311:1565; 315:839, entre otros. Así, cuando se invocaba la disparidad de trato entre deudores morosos y en cumplimiento normal de sus obligaciones, según el régimen de excepción previsto por el art. 39 del dec. 1387/01 y normas complementarias. Máxime que la actividad de las entidades bancarias -la intermediación entre la oferta y demanda de recursos financieros- afecta en forma directa e inmediata todo el espectro de la política monetaria y crediticia en que se hayan involucrados vastos intereses económicos y sociales (Fallos, 303:1776). (CSN, 12-5-2009, "Coronel Jorge F. c. Estado Nacional y ot. s/amparo", La Ley, 2009 C, p. 623).

28 Fallos, 308:1848; 329:3089; entre otros.

29 R.H.S. 2083, 20-10-2009, "Sosa E.E. c. Prov. de Santa Cruz".

30 CSN, “Badaro c. ANSES”, consid. 15 y 16, Fallos, 329:3089; LL, 2006-D, p. 801.

31 CSN, 27-11-2007, “Badaro II”, B. 675. XLI, IMP 2008-1, 95. 
Debe corroborar, en primer lugar, si el órgano político cumplió con su deber constitucional de reconocer los derechos y, a tal efecto, diseñar políticas públicas tendientes a asegurar su efectiva vigencia. En segundo término, corresponde al juzgador determinar si la política o el programa a tal efecto creados son razonables, es decir, si se ajustan a los estándares constitucionales y, asimismo, si resultan adecuados para satisfacer los derechos. Si los mencionados programas cumplen con tales presupuestos, ninguna consideración corresponde hacer a los jueces sobre políticas alternativas. Finalmente, y en tercer lugar, es necesario que el magistrado controle y compruebe si, una vez delineadas las políticas y creados los programas respectivos, éstos efectivamente se cumplen.

4. Ahora bien, la genérica función de garantía judicial se lleva a cabo naturalmente con diferentes tonalidades según sean las materias en debate. Hemos expuestos sus alcances y límites en general en un cuadro que puede considerarse aún inconcluso, en plena construcción. No es nuestro objetivo agotar el tratamiento de las distintas políticas públicas, que son tantas y tan diversas como las vastísimas áreas propias de las tradicionales incumbencias estatales, tan extendidas en el modelo del Estado Democrático de Derecho, comprensivo del Estado de bienestar. Como muestra nos vamos a detener tan solo en el control judicial de ciertas políticas públicas, representativas en la experiencia práctica de la forma cómo se viene ejerciendo aquella función esencial confiada a los jueces.

Hemos aludido antes a la intervención de la CSN en las políticas de la seguridad social y la aplicación de la movilidad de los haberes jubilatorios, en el caso "Badaro". Hay, desde luego, otros varios sectores en los que el control judicial puede considerarse igualmente paradigmático y donde el Alto Tribunal ha formulado contribuciones señeras incursionando de un modo $u$ otro para influir en la configuración de las políticas respectivas. Basta pensar en los casos "Verbitsky"32 y "Lavado"33, donde se diseñaron remedios para suplir graves omisiones contrarias a los derechos fundamentales de los detenidos en establecimientos penitenciarios y policiales, a partir de determinados estándares consagrados en instrumentos internacionales con la finalidad de preservar la dignidad de la persona humana, exhortándose a los poderes políticos para que adecuen la legislación en materia de prisión preventiva y excarcelación a los estándares mínimos internacionales ${ }^{34}$. O el no menos resonante caso "Beatriz Mendoza"35, sobre la contaminación del Riachuelo. Al margen claro, de las conocidas vicisitudes por las que viene transcurriendo la ejecución de las

32 CSN, 3-5-2005, Fallos, 328:1146.

33 CSN, 6-9-2006, Fallos, 329:3863; 13-2-2007, Fallos, 330:111; 20-3-2007, Fallos, 330:1135.

34 Un amplio análisis puede verse en COURTIS C., Tutela judicial efectiva y afectaciones colectivas de derechos humanos en J.A., 2006-II, pp. 1225 y ss. Asimismo: GULLCO H., Garantías en el proceso penal en La Corte y los derechos. 2005-2007, ADC, Siglo XXI ed., Bs. As., 2008, pp. 314-324.

35 Fallos, 329:2316. 
respectivas decisiones ${ }^{36}$, que no empañan sin duda los sanos propósitos que generaron la intervención en función de control judicial.

5. Hay otros casos que sin resultar tan estentóreos o enfáticos en punto a imponer acciones concretas a los poderes políticos, de todos modos producen por la propia autoridad y fundamentos en que se sustenta el Tribunal, una profunda incidencia en las políticas públicas del sector. Es lo que ha acontecido en el plano tan conflictivo de las políticas para combatir el tráfico de drogas. Ha de convenirse que las recientes decisiones de la CSN han influenciado de modo palmario en la promoción de los paradigmas de lucha contra el narcotráfico. Es sabido que en el marco de la globalización del combate contra ese flagelo universal, desde EE.UU. y los organismos internacionales de la ONU, se impulsó durante las últimas décadas, con mayor o menor intensidad, el paradigma de línea dura del total prohibicionismo, que se extendía indiscriminadamente al consumo y criminalizaba a los consumidores. Entre nosotros, la ley 23.737 de estupefacientes, de 1989, en esa línea, castiga la tenencia de drogas para uso personal. Sin embargo, la CSN en fallo del 25 de agosto de 2009, "Arriola" ${ }^{37}$, declaró la inconstitucionalidad del segundo párrafo del art. 14 de dicha ley en un caso de tenencia de marihuana, por no superar el test constitucional de racionalidad. A partir de ese entonces volvió a abrirse un amplio debate en el seno de la sociedad, en el nivel doctrinario y principalmente en los ámbitos políticos, que alienta profundos cambios en las políticas públicas orientados a la reformulación de una serie de estrategias y medidas enfocadas -en contraposición con el modelo anterior- más hacia la prevención de las adiciones que a la penalización del consumo personal de ciertas drogas, como la marihuana hasta ciertas dosis, y sin perjuicio de mantenerse la criminalización de otras clases de psicofármacos ilegales.

Si bien es cierto que el Alto Tribunal siguió en su doctrina un derrotero pendular, zigzagueante, de todos modos puede considerarse que los criterios acogidos en "Arriola", en tanto se sustentan en la reforma constitucional de 1994, que introdujera profundos cambios en la política criminal del Estado, suponen una lectura razonable de los estándares respectivos. No puede dejar de memorarse que la Corte se había pronunciado a favor de la criminalización de la tenencia de estupefacientes para consumo personal en "Colavini" ${ }^{38}$, de 1978; después con nueva integración en "Bazterrica" y "Capalbo"39, ambos de 1986, se inclinó por la tesis contraria; y más adelante, siempre por mayoría, en "Montalvo ${ }^{40}$, de 1990, había retomado la tesis de la incriminación. Como en otros temas álgidos, la doctrina de la Corte ha mostrado

\footnotetext{
36 Una amplia reseña sobre el tema puede verse en las notas periodísticas de "La Nación", Bs. As., 17 de marzo de 2011, p. 14 y 17 de febrero de 2012, p. 16.

37 La Ley, 2009-E, p. 466.

38 Fallos, 300:254.

39 Fallos, 308:1392.

$40 \quad$ Fallos, 313:1333.
} 
señalados vaivenes buena parte de cuya explicación puede encontrarse en las cambiantes integraciones al conjuro de la renovación de los elencos políticos de turno. Sin embargo, no es menos exacto que las valoraciones comunitarias sufrieron durante todo ese tiempo transformaciones trascendentes que son las que, precisamente, brindan sustento a la postura adoptada ahora por el Tribunal.

La contribución de la CSN indudablemente ha resultado relevante para la promoción del cambio de paradigma. El Alto Tribunal no solo se limitó a declarar la inconstitucionalidad del precepto que castiga la tenencia de ciertas drogas para uso personal, sino que además exhortó a todos los poderes públicos a asegurar una política de Estado contra el tráfico ilícito de estupefacientes y a adoptar medidas de salud preventivas, con información y educación disuasiva del consumo, enfocada sobre todo en los grupos más vulnerables, especialmente los menores, a fin de dar adecuado cumplimiento a los tratados internacionales sobre derechos humanos suscriptos por el país. De ese modo, dejó allanado el camino para el avance de la modificación en sentido amplio de las íntegras políticas públicas en la materia. Claro que corresponde al Congreso el diseño y programación de los componentes del nuevo paradigma, y al PEN su implementación, ejecución, seguimiento y control. Poner el acento en la prevención de las adicciones, organizando las estrategias más adecuadas; determinar cuáles son las drogas permitidas para el consumo personal y bajo qué límites, y cuáles las prohibidas (v. gr. cocaína y drogas sintéticas en general); mitigar, y cómo, los efectos de éstas últimas (especialmente el "paco"); asistir, con cuáles fondos (públicos) y de qué manera a los adictos. Se trata de los componentes centrales de la política pública que tiene por objetivo esencial el control y reducción de la demanda y la oferta en el mercado de las drogas, especialmente aquellas sintéticas elaboradas a partir de precursores químicos, acentuar la persecución del tráfico ilegal y el castigo ejemplar a los productores y distribuidores, los "peces gordos" verdaderos "agentes del mal". Objetivos cuyo logro que naturalmente requiere de una pluralidad de acciones que únicamente los poderes políticos pueden diagramar, evaluar en sus costos operativos y ejecutar; claro que con sujeción y respeto de los derechos y garantías fundamentales cuya tutela, una vez más, corresponde al Poder Judicial, que asume de ese modo el control de racionalidad de la política pública imperante.

\section{La política ambiental y el Caso "Salas Dino y otros"}

Es bien conocido el activismo que la Corte viene desarrollando en materia ambiental, campo propicio para la fijación de pautas y criterios profundamente innovadores. Entre las más recientes, se destacan las sucesivas resoluciones pronunciados en la causa "Salas Dino y otros s. Provincia de Salta y Estado Nacional", que ilustran acabadamente sobre los alcances y límites de la intervención judicial y la relación de coordinación entre los actos de los distintos poderes del Estado en el marco de las atribuciones interjurisdiccionales. 
1. Un grupo de personas, comunidades indígenas y asociaciones criollas dedujeron en 2008 ante el Alto Tribunal acción de amparo colectivo a fin de que se disponga el cese inmediato y definitivo de los desmontes y talas indiscriminadas de los bosques nativos situados en varios departamentos de la Provincia de Salta, solicitando se declare la nulidad absoluta e insanable de las autorizaciones otorgadas a esos efectos y la prohibición de otorgarlas para el futuro; como asimismo, se imponga a las demandas el deber de recomponer y restablecer el ambiente al estado anterior a la producción del daño o la indemnización sustitutiva correspondiente. El Tribunal, mediante resolución del 29 de diciembre de $2008^{41}$ asumió el conocimiento de la causa, aún sin pronunciarse sobre su competencia, argumentando que la gravedad de los hechos que se denunciaban y a raíz de los cuales se responsabilizaba a la Provincia de Salta por el incumplimiento de obligaciones legales, y el consiguiente desmedro de diversos derechos y garantías consagrados en la Constitución, en la LGA y en instrumentos internacionales, exigían de la Corte el ejercicio del control encomendado a la justicia sobre las actividades de los otros poderes del Estado. En ese marco, resultaba procedente la adopción de las medidas conducentes que, sin menoscabar las atribuciones de estos últimos, tiendan a sostener la observancia de la $\mathrm{CN}$, sin que pueda verse en ello, sostuvo, una intromisión indebida del Poder Judicial, reiterando su doctrina de Fallos, 330:111, 328:1146, entre otros (consid. 2). Invocando su condición de custodio de las garantías constitucionales, dispuso medidas de instrucción del trámite de la causa, ordenando a título de diligencia preliminar que el Estado provincial informe detalladamente sobre las personas que hubieren solicitado y obtenido autorizaciones de desmontes y talas de bosques nativos en las áreas en cuestión y convocó a audiencia para que las partes comparezcan a expedirse en forma oral y pública ante el Tribunal sobre los hechos denunciados. Por último, considerando que mediaba una grave afectación al medio ambiente, acordó la medida cautelar solicitada, ordenando de manera provisional y luego de oídas las partes, el cese de los referidos desmontes y talas autorizados por la Provincia. Por su resolución del 26 de marzo de $2009^{42}$ se impuso a la administración que otorgaba los premisos para la tala la obligación de efectuar el adecuado balance entre riesgos y beneficios, tomando en consideración el impacto ambiental acumulativo. La aplicación del principio precautorio, sostuvo, implica armonizar la tutela del ambiente y el desarrollo, mediante un juicio de ponderación razonable. Sin perjuicio, claro, de la potestad que la Corte se reserva para el control de los actos y medidas que se adopten en aquella sede, con sujeción al mismo criterio de razonabilidad. Ulteriormente, mediante resolución del 30 de junio de 2009 admitió las presentaciones efectuadas por varias fundaciones ambientalistas, a título a amicus curiae; intimó asimismo a la Secretaría de Medio Ambiente de la Nación y a la autoridad provincial a acompañar informes de impacto ambiental acumulativos,

\footnotetext{
41 Fallos 331:2925.

$42 \quad$ La Ley, 2009-B, p. 683.
} 
necesarios para evaluar el mantenimiento de la medida cautelar. Por último, ante el dictado de diversos actos legislativos y reglamentarios por parte de la Provincia, la Corte se pronunció mediante la resolución del 13 de diciembre de $2011^{43}$, con la finalidad de encausar definitivamente el conflicto en el marco de las atribuciones propias de cada uno de los poderes estatales.

2. Sostuvo el Tribunal que las diversas y sobrevinientes normas de Ordenamiento Territorial de los Bosques Nativos de la provincia, el decreto reglamentario por el cual se aprobó el soporte cartográfico para la delimitación de las diversas áreas y categorías de conservación, la creación de Agencias como autoridades de aplicación de los sistemas respectivos, al igual que el acto administrativo mediante el cual se pusiera en marcha la delimitación definitiva de las áreas boscosas que ocupan las comunidades indígenas y que se consideran, de manera precautoria, bajo prohibición de ejecución de autorizaciones de desmonte pendientes, han implicado el desarrollo de políticas públicas ambientales tendientes a instaurar un régimen tuitivo. La Provincia ha ejercido su jurisdicción local en la materia y el dominio originario de sus recursos naturales (arts. 41 y 124, CN), con lo que se evidencia la voluntad política del gobierno de superar el conflicto que diera origen al proceso. En consecuencia de todo ello, el Tribunal dispuso el levantamiento de la medida cautelar, por no subsistir las circunstancias que determinaran oportunamente su dictado, tres años antes; sin perjuicio de la carga de los titulares de los permisos suspendidos de adecuarse a las condiciones establecidas en las nuevas normas provinciales, como también del encauzamiento de las atribuciones del organismo nacional competente.

Con el referido pronunciamiento, la Corte considera que se han alcanzado los propósitos perseguidos con la intervención asumida en el pleito y, en consecuencia, resuelve desprenderse del conocimiento en la causa. Al mismo tiempo que declara su incompetencia en la vía originaria del art. 117 de la $\mathrm{CN}$, dispone la remisión de las actuaciones a la Corte de Justicia salteña para que examine si la acción de amparo en trámite corresponde a su competencia originaria o, en su defecto, para que sea asignada al tribunal provincial que resulte competente.

3. De ese modo, la CSN demarcó nítidamente el marco de las respectivas incumbencias constitucionales, deslindando por un lado las propias en correlato con las pertenecientes a los poderes políticos de la Nación y, por otro, las que derivan del sistema federal de gobierno (arts. 5 y 121, CN). Su intervención circunstancial en una causa que a la postre declaró no encuadrar en su competencia originaria, quedó abierta ante la gravedad de los hechos denunciados por los actores y la clara afectación al medio ambiente que producían las actividades de desmonte y tala indiscriminada, que exigían de la Corte la adopción de las medidas conducentes. Semejante situación justificaba la suspensión cautelar de tales actividades y, en

43 La Ley, 2012, fallo 116.145. 
paralelo, la gestión del proceso mediante la instrucción de la causa, a través de procedimientos $\mathrm{Ad} \mathrm{Hoc,} \mathrm{típicos} \mathrm{de} \mathrm{los} \mathrm{conflictos} \mathrm{colectivos} \mathrm{de} \mathrm{interés} \mathrm{público:} \mathrm{fijación}$ de audiencia pública para oír las exposiciones de las partes - previa a la suspensión cautelar-, requerimiento de información específica a los Estados demandados y, especialmente, de estudios de impacto ambiental acumulativo producido por las actividades cuestionadas sobre el clima, el paisaje, el ambiente en general y en las condiciones de vida de los habitantes, y en los que, a su vez, debía proponerse soluciones armonizadoras de los valores contrapuestos involucrados. Hasta aquí, la Corte gestionaba a su manera la suspensión cautelar, mientras colectaba diversos elementos de juicio útiles a la ulterior decisión sobre el mérito. Sin embargo, fruto de sus requerimientos, las autoridades provinciales ejecutaron de modo paulatino y en ejercicio de sus competencias constitucionales, una serie de actos legislativos y administrativos que configuraban, según el Tribunal, políticas públicas ambientales, verificado lo cual no quedaba sino desprenderse del conocimiento de la causa, teniendo por alcanzados los propósitos perseguidos. Es que, como se había declarado en el precedente de Fallos, 318:992, corresponde reconocer a las autoridades locales la facultad de aplicar los criterios de protección ambiental conducentes para el bienestar de la comunidad para que gobiernan; el ambiente es responsabilidad del titular originario de la jurisdicción (Fallos, 330:4234, entre otros).

La Corte, una vez más, encontró el camino para ejercer sus potestades como celoso guardián de los derechos fundamentales de las personas, valiéndose de una causa en la que ni siquiera estaba en claro su competencia para dictar diversas medidas que, a la postre, impulsaron e incitaron la asunción de potestades propias de las funciones políticas de los demás órganos estatales. Dictadas las políticas públicas por las autoridades competentes, y verificada su congruencia con los principios constitucionales y las leyes de fondo ambientales, tuvo por concluida y cumplida su misión jurisdiccional.

4. Para integrar el cuadro, resulta de interés señalar que coetáneamente, la Corte se avocó al conocimiento de otras dos causas medioambientales que presentan algunas características similares, disponiendo medidas tempranas. Así en "Comunidad Indígena Toba La Primavera-Novogoh vs. Provincia de Formosa y otros, s/medida cautelar" ${ }^{\prime 4}$, una comunidad indígena denunció la realización de trabajos previos de desmonte y demarcación en terrenos de 609 has., ocupados por la referida comunidad, que a su vez había motivado el dictado de una medida cautelar de la Comisión Interamericana de Derechos Humanos. La Corte, mediante resolución del 20 de diciembre de 2011, ante la gravedad de los hechos denunciados y aplicando la doctrina sentada, entre otros, en "Salas Dino", Fallos 331:2925, convocó a todas las partes involucradas a una audiencia pública; con reserva de lo que en definitiva resuelva oportunamente sobre su propia competencia.

44 La Ley, 2012, supl. 3-1-2012, fallo 116.020. 
En la misma fecha tomó intervención en la causa "Provincia de Santiago del Estero vs. Cía. Azucarera Concepción S.A. y otro, s/amparo ambiental”"4, donde se promoviera demanda por daño ambiental colectivo contra los propietarios de los ingenios Concepción y La Florida de la Provincia de Tucumán, a fin de hacer cesar la contaminación del lago del dique frontal de las Termas de Río Hondo, por el volcado de vinaza sobre los cursos de agua que desembocan en aquel y que conforman la cuenca Salí-Dulce; así como la recomposición del ambiente dañado o la compensación correspondiente. La Corte, sin perjuicio de dejar a salvo lo que resuelva en definitiva sobre su competencia y la legitimación del Defensor del Pueblo de Santiago del Estero, dispuso requerir a la Secretaría de Ambiente y Desarrollo Sustentable de la Nación informe sobre el grado de avance de las acciones impulsadas en ese ámbito para la protección del ecosistema en cuestión, desestimando por prematura la medida cautelar requerida para que se suspenda la producción de las actividades pretendidamente contaminantes.

5. En definitiva, como se ha señalado con razón ${ }^{46}$, la revisión judicial se enfoca principalmente en dos instrumentos de gestión y política ambiental: el ordenamiento territorial y la evaluación de impacto ambiental con la necesaria participación ciudadana. Con la particularidad que en los casos en que medían razones de urgencia, la vía del amparo y las medidas cautelares anticipatorias se admiten como técnicas procesales idóneas, entre otras, para salvaguardar los derechos fundamentales "sensibles" en juego. Todo en el marco inédito de un proceso ad hoc típico de la "democracia deliberativa", modelado in itinere por los propios jueces con el objetivo último de ejercer de modo cabal la función judicial de garantía.

\section{Algunas conclusiones de Cierre}

A esta altura del discurso estamos en condición de formular ciertas conclusiones:

1. En el modelo de Estado Democrático de Derecho se reserva a los jueces misiones trascendentes, verdaderas funciones de garantía que se ejercitan de modo auxiliar y no sustitutivo, aunque siempre "contra mayoritariamente", para asegurar la efectiva operatividad de los derechos fundamentales. El arduo desafío de articular semejantes atribuciones con las funciones políticas a cargo de los restantes poderes, conduce al análisis de los conflictos concretos en los casos que se plantean al conocimiento judicial, más allá de las formulaciones abstractas más propias de la doctrina autoral.

2. El ámbito del ejercicio de las funciones de garantía judiciales viene acotado, genéricamente, a partir de la premisa que los jueces deben por regla acatar las políticas públicas estructurados por los poderes de gobierno en consonancia con los manda-

$45 \quad$ La Ley, 2012-B, supl. 28-2-2012, fallo 116.106.

46 SBDAR C.B., Revisión judicial de los instrumentos de gestión y política ambiental..., La Ley, 2009-F, pp. 1146 y ss. 
tos constitucionales. No es que deban abstenerse de toda consideración acerca de dichas políticas, han de escrutarlas en su correspondencia con aquellos mandatos superiores mediante el test fundado de constitucionalidad-convencionalidad de los actos y aún de las omisiones o defecciones. La autoridad de los jueces surge de los propios límites que ellos mismos se imponen en el ejercicio de la función de garantía.

3. La intervención de los jueces en función de garantía y el contenido eminentemente público de la jurisdicción brindan sustento a novedosos modelos de proceso y de gestión, caracterizados por la apertura de un amplio "diálogo" (método "dialogal"), típico de los conflictos colectivos de interés público, que posibilita además una participación más colaborativa de la administración pública, los entes involucrados y aún los terceros amigos del tribunal. El proceso se convierte en un espacio abierto de "democracia deliberativa" para la búsqueda de las soluciones estructurales, a través del cual los jueces no solo ejercen el control de las políticas públicas sino que, a menudo, inducen su configuración o mejora por los poderes de gobiernos. Están convocados a ejercer novedosos papeles como gestores, moderadores, componedores y arbitradores, cada vez que se demuestra una "disfunción política", un desvío del natural curso del interés público, en el marco del clásico control judicial de constitucionalidad ahora amplificado para brindar cabida a las nuevas o renovadas misiones.

4. El ejercicio de la función judicial de garantía se articula en tiempos y acciones sucesivas: $a$ ) verificación del cumplimiento del deber constitucional de los poderes políticos de diseñar e instrumentar las políticas públicas necesarias para la efectivización de los derechos y garantías consagradas en los textos supremos; $b$ ) ponderación de la razonabilidad de tales políticas públicas, a través del test de correspondencia y adecuación con los estándares constitucionales y convencionales. Si la verificación es positiva, le está vedado entrar al análisis de la oportunidad y conveniencia, o formular políticas alternativas; $c$ ) si resultare que existe defección del deber a cargo de los poderes políticos, sea por omisión absoluta o por falta de correspondencia de las políticas con estándares supremos, se abre un ancho margen de posibilidades que prudentemente evaluará el juez: exhortación, inducción, proposición de líneas de políticas y programas u otras vías adecuadas; $d$ ) comprobación de la efectiva implementación de las políticas diseñadas y los programas respectivos, que han de conducir en definitiva a la efectividad de los derechos en cuestión.

5. La CSN en su actual composición, a partir de 2005 ha venido consolidando su doctrina en torno de las funciones de garantía que le competen como tribunal supremo y custodio de los derechos fundamentales. Está desplegando un inteligente y equilibrado activismo sustantivo y procesal, en especial para la tutela efectiva de los derechos fundamentales "sensibles", aquellos derechos "impregnados de un sentido de esencial fundamentabilidad”. 
6. Resultan altamente valiosas para el logro de esos fines las técnicas e instituciones procesales que el propio Tribunal ha diseñado y puesto en práctica para atender eficazmente el despacho de los conflictos colectivos de interés público, y que en su conjunto integran un espacio típico de la "democracia deliberativa", que contribuye señaladamente a la institucionalidad republicana. 